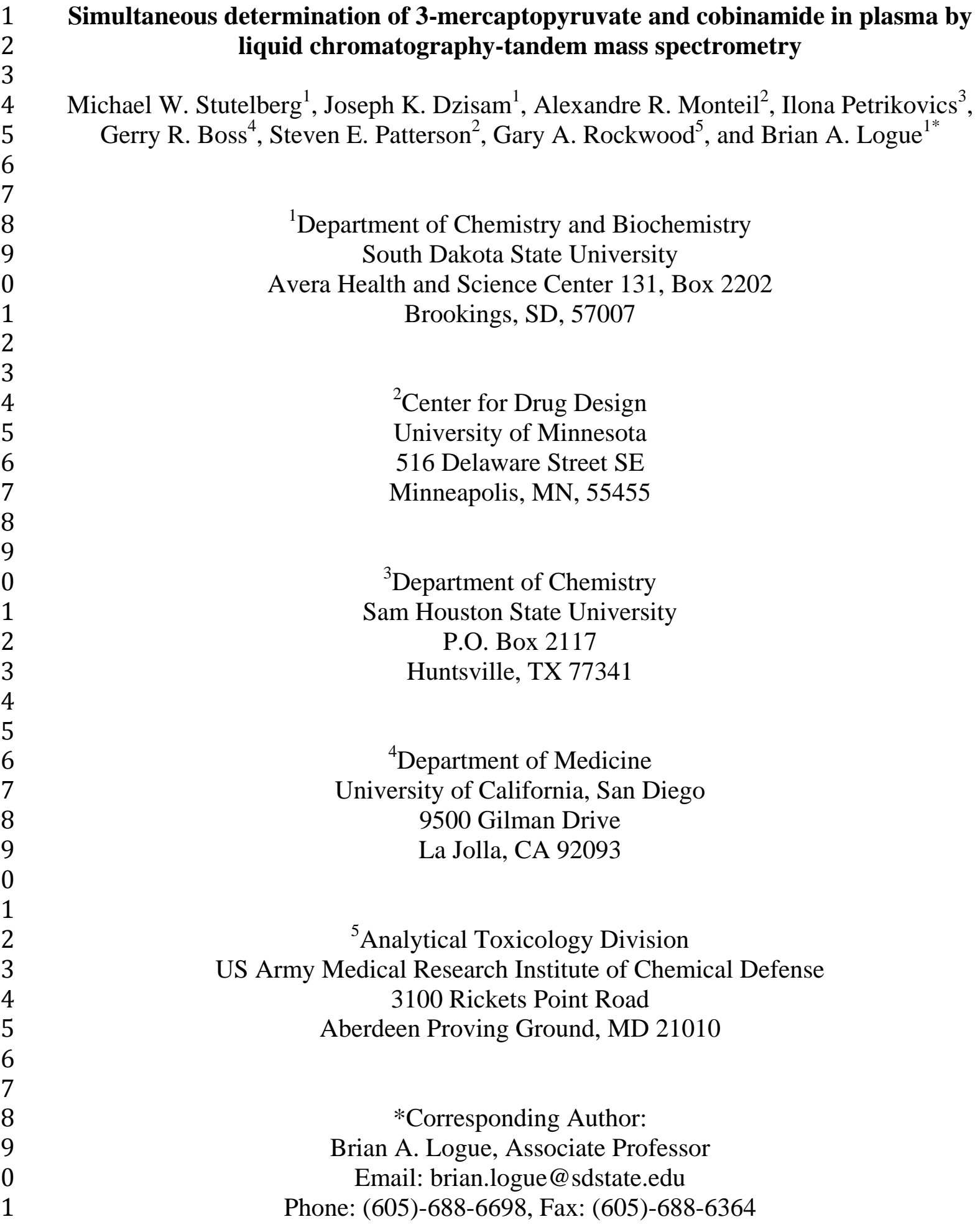

\section{${ }^{1}$ Department of Chemistry and Biochemistry}

South Dakota State University

Avera Health and Science Center 131, Box 2202

Brookings, SD, 57007

${ }^{2}$ Center for Drug Design

University of Minnesota 516 Delaware Street SE

Minneapolis, MN, 55455

${ }^{3}$ Department of Chemistry Sam Houston State University P.O. Box 2117 Huntsville, TX 77341

${ }^{4}$ Department of Medicine University of California, San Diego 9500 Gilman Drive La Jolla, CA 92093

${ }^{5}$ Analytical Toxicology Division US Army Medical Research Institute of Chemical Defense 3100 Rickets Point Road Aberdeen Proving Ground, MD 21010

*Corresponding Author: Brian A. Logue, Associate Professor Email: brian.logue@sdstate.edu Phone: (605)-688-6698, Fax: (605)-688-6364

(C) 2015. This manuscript version is made available under the Elsevier user license http://www.elsevier.com/open-access/userlicense/1.0/ 
LC-ESI-MS/MS of 3-mercaptopyruvate and cobinamide

\section{Abstract}

The current suite of Food and Drug Administration (FDA) approved antidotes

49 (i.e., sodium nitrite, sodium thiosulfate, and hydroxocobalamin) are effective for treating

50 cyanide poisoning, but individually, each antidote has major limitations (e.g., large

51 effective dosage or delayed onset of action). To mitigate these limitations, next-

52 generation cyanide antidotes are being investigated, including 3-mercaptopyruvate (3-

$53 \mathrm{MP}$ ) and cobinamide (Cbi). Analytical methods capable of detecting these therapeutics

54 individually and simultaneously (for combination therapy) are essential for the

55 development of 3-MP and Cbi as potential cyanide antidotes. Therefore, a liquid

56 chromatography-tandem mass-spectrometry method for the simultaneous analysis of 3-

57 MP and Cbi was developed. Sample preparation of 3-MP consisted of spiking plasma

58 with an internal standard $\left({ }^{13} \mathrm{C}_{3}-3-\mathrm{MP}\right)$, precipitation of plasma proteins, and derivatizing

59 3-MP with monobromobimane to produce 3-mercaptopyruvate-bimane. Preparation of

60 Cbi involved denaturing plasma proteins with simultaneous addition of excess cyanide to

61 convert each Cbi species to dicyanocobinamide $\left(\mathrm{Cbi}(\mathrm{CN})_{2}\right)$. The LODs for 3-MP and Cbi

62 were $0.5 \mu \mathrm{M}$ and $0.2 \mu \mathrm{M}$, respectively. The linear ranges were 2-500 $\mu \mathrm{M}$ for 3-MP and

$63 \quad 0.5-50 \mu \mathrm{M}$ for Cbi. The accuracy and precision for 3-MP were $100 \pm 9 \%$ and $<8.3 \% \mathrm{RSD}$,

64 respectively. For $\mathrm{Cbi}(\mathrm{CN})_{2}$, the accuracy was $100 \pm 13 \%$ and the precision was $<9.5 \%$

65 RSD. The method presented here was used to determine 3-MP and Cbi from treated

66 animals and may ultimately facilitate FDA approval of these antidotes for treatment of

67 cyanide poisoning.

68

69 Keywords: Cyanide antidote, sulfanegen, mass spectrometry. 
LC-ESI-MS/MS of 3-mercaptopyruvate and cobinamide

\section{$70 \quad$ 1. Introduction}

71 Although the current suite of Food and Drug Administration (FDA) approved

72 cyanide $\left(\mathrm{HCN}\right.$ and $\mathrm{CN}^{-}$, inclusively represented as $\mathrm{CN}$ ) antidotes (i.e., sodium thiosulfate,

73 sodium nitrite, and hydroxocobalamin $(\mathrm{Cbl})$ ) are effective for treating cyanide poisoning,

74 each has major limitations [1-3]. Therefore, next generation cyanide antidotes, are being

75 developed. Two of these next generation antidotes, cobinamide (Cbi) and sulfanegen (i.e.,

76 dimer of 3-mercaptopyruvate (3-MP)), have shown promise in remedying the limitations

77 of currently approved antidotes. For example, although Cbl (i.e., the current FDA

78 approved direct cyanide binding treatment [4-6]) works well to detoxify cyanide [7-9],

79 and its potential adverse effects are generally mild [10,11], it is very large and can only

80 sequester one $\mathrm{CN}$ ion per $\mathrm{Cbl}$ molecule. Therefore, very large doses of $\mathrm{Cbl}$ must be

81 administered intravenously over minutes, making it a poor antidote in mass casualty

82 situations [11]. To address the disadvantages of Cbl, Cbi is being developed as an

83 alternative direct cyanide binding agent. Cbi is the penultimate precursor in the biological

84 production of $\mathrm{Cbl}$ and is naturally found in human serum and bile $[2,12]$. Cbi works by

85 sequestering cyanide from its active site (i.e., the heme A site in cytochrome $\mathrm{C}$ oxidase).

86 Structurally, Cbi lacks Cbl's dimethylbenzimidazole ribonucleotide tail [12, 13].

87 Consequently, it has a smaller mass, greater overall affinity towards cyanide, $\left(\mathrm{K}_{\mathrm{f}} \approx 10^{22}\right)$

$88[14,15]$, higher water solubility, and the ability to bind two cyanide ions [12, 14-17]. Cbi

89 has been shown to have 3-10 times more potency than hydroxocobalamin, depending on

90 the formulation [2, 18]. The main difference between Cbi formulations is the ligand

91 identity, with the current formulation using nitrite ions, to improve absorption during

92 intramuscular administration [15]. 
93 Another treatment strategy for cyanide poisoning is conversion of cyanide to the

94 much less toxic thiocyanate $\left(\mathrm{SCN}^{-}\right.$, represented herein as $\left.\mathrm{SCN}\right)$ with sulfur donors and

95 native sulfurtransferase enzymes as catalysts. Sodium thiosulfate is currently the only

96 FDA approved sulfur donor for treating cyanide toxicity. Although sodium thiosulfate is

97 effective, it has a slow onset of action attributed to slow entry into cells and the

98 mitochondria [1]. This necessitates its use in combination with faster acting therapeutics,

99 typically nitrites. Also, sodium thiosulfate utilizes the enzyme rhodanese, which is

100 primarily found in the liver and kidneys [19, 20], leaving the heart and central nervous

101 system less protected [19].

102 Because of the disadvantages of thiosulfate, alternate sulfur donors are being

103 investigated, including 3-MP $[3,16,19]$. The conversion of $\mathrm{CN}$ to SCN by 3-MP is

104 catalyzed by 3-MP sulfurtransferase (3-MST) [3, 20, 21]. This conversion occurs

105 primarily in blood or tissue areas near blood. The highest concentrations of 3-MST are

106 found in the liver and kidneys, with heart, brain and lungs also supporting the enzyme

107 [20, 22-24]. In contrast to rhodanese, 3-MST is distributed in both the cytosol and

108 mitochondria, allowing the reaction of 3-MP with $\mathrm{CN}$ to occur primarily in the cytosol,

109 with the remaining $\mathrm{CN}$ distributing into the mitochondria where it is metabolized by

110 rhodanese. Although 3-MP is an effective sulfur donor, it readily degrades in the blood.

111 Therefore, several prodrugs of 3-MP (i.e., chemical compounds that convert to 3-MP

112 upon administration), inclusively called sulfanegen, were developed. In multiple studies,

113 intramuscularly administered sulfanegen was highly effective in reversing cyanide

114 toxicity $[3,19,22,25,26]$. 
115 Although both Cbi and 3-MP have advantages as individual antidotes, they work

116 by distinct mechanisms. Therefore, the combination of these two compounds has been

117 suggested to provide greater protection than the compounds alone [16]. In general, the

118 main advantages of combination therapeutics are 1) lowering the dose of the individual

119 components, which potentially leads to minimized side effects, and 2) allowing drugs

120 with distinct pharmacokinetic profiles to be administered simultaneously, potentially

121 extending the therapeutic window of individual treatments (e.g., combining a fast-acting

122 quickly metabolized compound with a longer acting therapeutic). As a combination

123 therapy, Cbi and sulfanegen have been administered intramuscularly to treat cyanide

124 poisoning in mice [16] with additive protection against cyanide toxicity.

125 In order to determine the stability and pharmacokinetic properties of a 3-MP and

126 Cbi combination therapy, and to ultimately obtain FDA approval, a validated analytical

127 method is essential. Although previous analytical methods have been developed to

128 individually determine 3-MP or various Cbi species [12, 27-36], there is a need to

129 develop an analytical technique to simultaneously determine Cbi and 3-MP in order to

130 reduce effort, analysis costs, and minimize necessary sample volumes. Therefore, the

131 focus of this project was to develop an analytical method to simultaneously determine

132 and quantify dicyanocobinamide $\mathrm{Cbi}(\mathrm{CN})_{2}$ and 3-MP using LC-MS-MS.

\section{2. Experimental}

135 2.1. Reagents and standards

136 All solvents were LC-MS grade unless otherwise noted. Ammonium formate and

137 3-mercaptopyruvate (3-MP; $\mathrm{HSCH}_{2} \mathrm{COCOOH}$ ) were purchased from Sigma-Aldrich (St 
138 Louis, MO, USA). Acetone (HPLC grade, 99.5\%) was purchased from Alfa Aesar (Ward

139 Hill, MA, USA). Cobinamide (C48H72CoN11O8; $989.76 \mathrm{~g} / \mathrm{mol}$ ) was obtained from the

140 Department of Medicine, University of California, San Diego (La Jolla, CA) [17].

141 Potassium cyanide, sodium hydroxide, and Millex® tetrafluoropolyethylene syringe

142 filters $(0.22 \mu \mathrm{m}, 4 \mathrm{~mm}$, Billerica, MA, USA) were obtained from Fisher Scientific

143 (Pittsburgh, PA, USA). Isotopically-labeled 3-MP $\left(\mathrm{HS}^{13} \mathrm{CH}_{2}{ }^{13} \mathrm{CO}^{13} \mathrm{COOH}\right)$ was

144 synthesized and provided by the Center for Drug Design, University of Minnesota

145 (Minneapolis, MN, USA) [3]. Monobromobimane (MBB, 3-(bromomethyl)-2,5,6-

146 trimethyl-1H,7H-pyrazolo[1,2-a]pyrazole-1,7-dione; $\mathrm{C}_{10} \mathrm{H}_{11} \mathrm{BrN}_{2} \mathrm{O}_{2}$ ) was obtained from

147 Fluka Analytical (Buchs, Switzerland) and a standard solution (500 $\mu \mathrm{M})$ was prepared in

148 LC-MS grade water and stored at $4{ }^{\circ} \mathrm{C}$. 3-MP calibration and QC standards were

149 prepared from a 3-MP stock solution $(10 \mathrm{mM})$ by serial dilution with swine plasma. The

150 internal standard solution was prepared from a stock solution of $1 \mathrm{mM}$ isotopically-

151 labeled 3-MP in LC-MS grade water and stored at $4{ }^{\circ} \mathrm{C}$. The $\mathrm{Cbi}\left(\mathrm{NO}_{2}\right)_{2}$ was prepared by

152 adding excess sodium nitrite $\left(4: 1 \mathrm{NO}_{2}^{-}: \mathrm{Cbi}\left(\mathrm{H}_{2} \mathrm{O}\right)(\mathrm{OH})^{+}\right)$to ensure two nitrite ligands

153 were bound to the $\mathrm{Cbi}[15]$. The $\mathrm{Cbi}(\mathrm{CN})_{2}$ was prepared by adding $3 \mathrm{x}$ the concentration

154 of cyanide to $\mathrm{Cbi}\left(\mathrm{H}_{2} \mathrm{O}\right)(\mathrm{OH})^{+}$in water. Note: Cyanide is toxic and is released as HCN in

155 neutral and acidic solutions. Therefore, all solutions were prepared in a well-ventilated

156 hood, and aqueous standards were prepared in $\geq 10 \mathrm{mM} \mathrm{NaOH}$.

158 2.2. Biological fluids

159 Animal plasma was obtained from four sources: two commercial vendors, a study

160 to evaluate the effectiveness of sulfanegen in rabbits, and a separate study to evaluate Cbi 
161 as a cyanide therapeutic in rats. Rat plasma (with $\mathrm{Na}$ Heparin as an anti-coagulant) was

162 purchased from Innovative Research (Novi, MI) and stored at $-80{ }^{\circ} \mathrm{C}$ until used. Rabbit

163 plasma (EDTA anti-coagulated) and swine plasma (EDTA anti-coagulated), were

164 purchased from Pel-Freeze Biological (Rogers, AR, USA) and stored at $-80{ }^{\circ} \mathrm{C}$ until

165 used. Swine plasma was initially chosen as the method development matrix because at

166 the time of major development of the analytical method, Cbi/sulfanegen combination

167 therapy studies were predominantly carried out in swine. Before the method was fully

168 validated, animal models of efficacy testing for Cbi and 3-MP were transitioned to rats

169 and rabbits, respectively. Therefore, evaluation of the method's ability to determine 3-MP

170 and Cbi from treated animals was carried out from rabbit and rat studies, respectively.

171 Rabbit plasma from a sulfanegen efficacy study was gathered at SRI International in

172 Menlo Park, California. The rabbits (New Zealand, 2.2-4.0 kg) had blood drawn pre-

173 dose. Sulfanegen $(136 \mathrm{mg} / \mathrm{kg})$ was administered intramuscularly and blood was drawn at

$17410 \mathrm{~min}, 30 \mathrm{~min}, 1,2$, 4, and $8 \mathrm{hrs}$ into heparin collection tubes. Plasma was immediately

175 separated from blood and frozen at $-70^{\circ} \mathrm{C}$. The samples were then shipped on dry ice to

176 South Dakota State University for analysis. Upon arrival, the plasma samples were stored

177 at $-80{ }^{\circ} \mathrm{C}$ until analyzed.

178 Rat plasma from a cobinamide/dimethyl trisulfide (DMTS) efficacy study was

179 gathered at the Department of Chemistry at Sam Houston State University, Huntsville,

180 Texas. Male rats (Charles River Breeding Laboratories, 315-320 g) had a catheter

181 implanted on the jugular vein and a DMTS solution $(960 \mu \mathrm{L}, 50 \mathrm{mg} / \mathrm{ml}$ in $15 \%$

182 Polysorbate 80) was injected into the right leg muscle. Nitrocobinamide (43 $\mu \mathrm{L}, 15$

$183 \mathrm{mg} / \mathrm{kg}$ ) was injected into the left leg muscle. Blood was then drawn into heparinized 
184 microcentrifuge tubes 3 at, 10, 20,35, and 90 min after cobinamide administration and

185 plasma was immediately separated from blood by centrifugation $\left(4^{\circ} \mathrm{C}, 13,500 \mathrm{rpm}\right)$ for

18610 mins. Plasma samples were then frozen at $-80^{\circ} \mathrm{C}$ and shipped on dry ice to South

187 Dakota State University for analysis. Upon arrival, the plasma samples were stored at -80

$188{ }^{\circ} \mathrm{C}$ until analyzed.

189 All animals were handled in accordance with the Guide for the Care and Use of

190 Laboratory Animals [37] and accredited by the Association for the Assessment and

191 Accreditation of Laboratory Animal Care (AAALAC) International. The Institutional

192 Animal Care and Use Committee (IACUC) at the respective institution approved the

193 experiment.

195 2.3. One-pot sample preparation of total Cbi

196 Simultaneous analysis of total Cbi and 3-MP was initially attempted using a one-

197 pot sample preparation method. Total Cbi was determined by denaturing plasma proteins, 198 converting each $\mathrm{Cbi}$ species to $\mathrm{Cbi}(\mathrm{CN})_{2}$ using excess cyanide and then analyzing the 199 concentration of $\mathrm{Cbi}(\mathrm{CN})_{2}$. Multiple protein denaturing schemes were evaluated in an 200 attempt to produce quantitative recovery of Cbi, while not degrading 3-MP, by varying

201 base concentration, cyanide concentration, and temperature. Initially, separate volumes of 202 swine plasma (in a $2 \mathrm{~mL}$ centrifuge vial) were spiked with $\mathrm{Cbi}(\mathrm{CN})_{2}, \mathrm{Cbi}\left(\mathrm{NO}_{2}\right)_{2}$, and/or $203 \mathrm{Cbi}\left(\mathrm{H}_{2} \mathrm{O}\right)(\mathrm{OH})^{+}(50 \mu \mathrm{L}, 1 \mathrm{mM}), 3-\mathrm{MP}(50 \mu \mathrm{L}, 1 \mathrm{mM})$, and aqueous 3-MP internal 204 standard $(100 \mu \mathrm{L}, 500 \mu \mathrm{M})$. Aqueous cyanide $(\mathrm{KCN})$ and strong base solutions $(100 \mu \mathrm{L}$ 205 each) were then spiked into the plasma, followed by vigorous mixing. To convert the Cbi 206 species to $\mathrm{Cbi}(\mathrm{CN})_{2}$, two concentrations of $\mathrm{CN}$ were evaluated, $1.5 \mathrm{mM}$ and $5 \mathrm{mM}$, which 
207 correspond to $3 \mathrm{x}$ and 10x molar equivalent of cyanide to the highest concentration of Cbi

208 calibration standard tested. To denature plasma proteins and release bound Cbi species,

209 two concentrations of $\mathrm{NaOH}(300 \mu \mathrm{M}$ and $1 \mathrm{mM})$ were evaluated. When elevated

210 temperatures were investigated for denaturing proteins, samples were heated on a heat

211 block (VWR International, Radnor, PA, USA) in a hood at $80^{\circ} \mathrm{C}$ for $15 \mathrm{~min}$. At the

212 conclusion of all denaturing protocols, acetone $(600 \mu \mathrm{L})$ was added to precipitate plasma

213 proteins. Samples were subsequently cold-centrifuged ( $\left.4^{\circ} \mathrm{C}\right)$ for $15 \mathrm{~min}$ at $13,100 \mathrm{RPM}$

$214(16,500 \times \mathrm{g})$. The supernatant $(700 \mu \mathrm{L})$ was transferred to a $4 \mathrm{~mL}$ glass vial and dried

215 under $\mathrm{N}_{2}$.

216

217 2.4. Quasi one-pot sample preparation of 3-MP and total Cbi

218 Because the one-pot sample preparation scheme gave undesired results, a quasi

219 one-pot sample preparation scheme was devised (i.e., samples were initially split and

220 then recombined for the duration of sample preparation). To a $2 \mathrm{~mL}$ centrifuge vial,

221 separate aliquots of 3-MP (50 $\mu \mathrm{L}$ in plasma), a 3-MP internal standard $(100 \mu \mathrm{L}$ of $15 \mu \mathrm{M}$

222 aqueous $\left.3-\mathrm{MP}_{-}{ }^{13} \mathrm{C}_{3}\right)$, and $\mathrm{Cbi}(\mathrm{CN})_{2}(50 \mu \mathrm{L}$ in plasma) were added and mixed. (Note: the

223 addition of $\mathrm{Cbi}(\mathrm{CN})_{2}$ prior to 3-MP internal standard caused 3-MP degradation in

224 prepared samples.) The samples were split evenly (100 $\mu \mathrm{L}$ each) into $2 \mathrm{~mL}$ centrifuge

225 vials designated as sub-samples A (i.e., total Cbi analysis) and B (i.e., 3-MP

226 determination). To sub-sample A, cyanide (10 mM KCN in $0.1 \mathrm{M} \mathrm{NaOH}$ ) was added and

227 samples were heated on a heat block at $80^{\circ} \mathrm{C}$ for $15 \mathrm{~min}$. While sub-sample A was being

228 heated, acetone $(300 \mu \mathrm{L})$ was added to sub-sample B to precipitate proteins. Sub-sample

229 B was then cold-centrifuged $\left(4^{\circ} \mathrm{C}\right)$ for $15 \mathrm{~min}$ at $13,100 \mathrm{RPM}(16,500 \mathrm{x} \mathrm{g})$ (Thermo 
230 Scientific Legend Micro 21R centrifuge, Waltham, MA, USA) and placed in the

231 refrigerator. After sub-sample A was removed from heat, acetone $(600 \mu \mathrm{L})$ was added to

232 precipitate plasma proteins and the sample was centrifuged. Afterwards, the supernatants

$233(600 \mu \mathrm{L}$ from $\mathrm{A}$, and $300 \mu \mathrm{L}$ from $\mathrm{B}$ ) were recombined in a $4 \mathrm{~mL}$ glass vial and dried 234 under $\mathrm{N}_{2}$.

\subsection{Sample preparation for $L C-M S-M S$}

237 For both the one-pot and quasi one-pot sample preparation schemes,

238 monobromobimane (100 $\mu \mathrm{L} 500 \mu \mathrm{M})$ and $5 \mathrm{mM}$ aqueous ammonium formate with $10 \%$

239 methanol $(100 \mu \mathrm{L})$ were added to the dried samples. The resulting solution was heated on

240 a block heater at $70{ }^{\circ} \mathrm{C}$ for 15 min to convert 3-MP to a 3-mercaptopyruvate-bimane (3-

241 MPB) complex [28]. Samples were filtered with a $0.22 \mu \mathrm{m}$ tetrafluoropolyethylene

242 membrane syringe filter into autosampler vials fitted with $150 \mu \mathrm{L}$ deactivated glass

243 inserts for LC-MS-MS analysis. It should be noted that when the number of samples were

244 above the maximum limit of the sample apparatus (e.g., the centrifuge), the samples that

245 were not being actively prepared were stored in a standard refrigerator $\left(4^{\circ} \mathrm{C}\right)$ to impede

246 degradation of 3-MP.

248 2.6. LC-MS-MS analysis of $\mathrm{Cbi}(\mathrm{CN})_{2}$ and $3-\mathrm{MPB}$

249 For LC-ESI-MS analysis a Shimadzu UHPLC (LC 20A Prominence, Kyoto,

250 Japan) coupled to an electrospray ionization quadrupole ion trap QTRAP 5500 LC-

251 MS/MS System (AB Sciex, Framingham, MA, USA) was used. The low-energy collision

252 dissociation tandem mass spectrometric analysis (CID-MS/MS) was conducted with the 
253 LINAC Collision Cell technology cell of the triple quadrupole/linear ion trap (LIT)

254 instrument. Separation was performed on a Phenomenex Synergy Max RP column (50 x

$2552.0 \mathrm{~mm}, 4 \mu \mathrm{m} 80 \AA$ ) with an injection volume of $10 \mu \mathrm{L}$ from samples stored in a cooled

256 autosampler $\left(15^{\circ} \mathrm{C}\right)$ and a flow rate of $0.25 \mathrm{~mL} / \mathrm{min}$. Mobile phase solutions consisted of

$2575 \mathrm{mM}$ aqueous ammonium formate with $10 \%$ methanol (Mobile Phase A) and $5 \mathrm{mM}$

258 ammonium formate in $90 \%$ methanol (Mobile Phase B). A gradient of 0 to $100 \%$ B was

259 applied over $3 \mathrm{~min}$, held constant for $0.5 \mathrm{~min}$, then reduced to $0 \% \mathrm{~B}$ over $1.5 \mathrm{~min}$. The

260 gradient produced a total run-time of $5.1 \mathrm{~min}$ and retention times of about 2.60 min for 3-

$261 \mathrm{MPB}$ and $2.9 \mathrm{~min}$ for $\mathrm{Cbi}(\mathrm{CN})_{2}$. The turbo ion-spray interface was heated at $500{ }^{\circ} \mathrm{C}$ with

262 zero air nebulization at 90 psi in positive ionization mode with drying and curtain gasses

263 pressures of $60 \mathrm{psi}$ each. The ion-spray voltage, declustering potential, collision cell exit

264 potential, and channel electron multiplier voltage were 4500, 121, 10, and $2600 \mathrm{~V}$,

265 respectively. Low-energy CID-MS/MS using multiple reaction-monitoring (MRM)

266 transition scans of precursor ion $\rightarrow$ product ion were used for analysis. The precursor $\rightarrow$

267 product ions were $311 \rightarrow 223.1$ and $311 \rightarrow 192.2 \mathrm{~m} / \mathrm{z}$ for $3-\mathrm{MPB}$ and $314 \rightarrow 223.1$ and

$268314 \rightarrow 192.2 \mathrm{~m} / \mathrm{z}$ for the internal standard-bimane complex with collision energies of 30.5

269 and $25 \mathrm{~V}$, respectively. The $\mathrm{Cbi}(\mathrm{CN})_{2}$ transitions of $1015.9 \rightarrow 930.5$ and $1015.9 \rightarrow 988.5$

270 were utilized with collision energies of 75.91 and $50.70 \mathrm{~V}$ and declustering potentials of

271249.42 and $237.79 \mathrm{~V}$, respectively. These transitions correspond to a precursor ion of

$272 \mathrm{Cbi}(\mathrm{CN})^{+}$, which includes both the monocyanocobinamide and dicyanocobinamide

273 species [32]. The $1064 \mathrm{~m} / \mathrm{z}$ transition of $\mathrm{Cbi}(\mathrm{CN})_{2}$ was not used because the $1015.9 \mathrm{~m} / \mathrm{z}$

274 transition offered greater sensitivity, lower LODs, and accounts for potentially

275 incomplete conversion of Cbi species to $\mathrm{Cbi}(\mathrm{CN})_{2}$. The dwell time was $100 \mathrm{~ms}$ for all 
LC-ESI-MS/MS of 3-mercaptopyruvate and cobinamide

276 transitions. Analyst software (Applied Biosystems version 1.5.2) was used for data

277 acquisition and analysis.

278

279 2.7. Calibration, quantification and limit of detection

280 For validation of the analytical method, we generally followed the FDA

281 bioanalytical method validation guidelines [38]. The lower limit of quantification

282 (LLOQ) and upper limit of quantification (ULOQ) were defined using the following

283 inclusion criteria: 1) calibrator precision of $<15 \% \mathrm{RSD}$, and 2) accuracy of $\pm 15 \%$ of the

284 nominal calibrator concentration back-calculated from the calibration curve. It is

285 important to note that calibration curves must be prepared each day for $\mathrm{Cbi}(\mathrm{CN})_{2}$ because

286 of daily variation in instrumental sensitivity and sample preparation with no internal

287 standard to correct for these errors. Calibration standards were initially prepared from 1-

$2881000 \mu \mathrm{M}(1,2,5,10,20,50,100,200,500,1000 \mu \mathrm{M})$ for 3-MP, with the range later

289 decreased to $2-500 \mu \mathrm{M}$. Calibration curves for $\mathrm{Cbi}(\mathrm{CN})_{2}$ were prepared from $0.5-500 \mu \mathrm{M}$

$290(0.5,1,2,5,10,20,50,100,200,500 \mu \mathrm{M})$ and later decreased to $0.5-50 \mu \mathrm{M}$.

291 To determine the accuracy and precision of the method, QCs $(\mathrm{N}=5)$ were prepared

292 at three concentrations not included in the calibration curve: 1.5 and $7.5 \mu \mathrm{M}$ (low QCs for

$293 \mathrm{Cbi}(\mathrm{CN})_{2}$ and 3-MP, respectively), 7.5 and $30 \mu \mathrm{M}$ (medium QCs for $\mathrm{Cbi}(\mathrm{CN})_{2}$ and 3-MP,

294 respectively), and 35 and $150 \mu \mathrm{M}$ (high $\mathrm{QCs}$ for $\mathrm{Cbi}(\mathrm{CN})_{2}$ and 3-MP, respectively). The

295 3-MP internal standard was prepared daily and added to each sample, calibration standard

296 and QC during sample preparation. Calibration curves and QCs, were prepared fresh each

297 day during intra-assay (daily) and inter-assay (over three separate days, within seven 
298 calendar days) analyses to calculate the intra-assay and inter-assay accuracy and 299 precision.

300 The limit of detection (LOD) was determined by analyzing multiple

301 concentrations of $3-\mathrm{MP}(0.2,0.5,1$, and $2 \mu \mathrm{M})$ and $\mathrm{Cbi}(\mathrm{CN})_{2}(0.2,0.5,1,2,3,4$, and 5

$302 \mu \mathrm{M}$ ) below the LLOQ and determining the lowest concentration that reproducibly

303 produced a signal-to-noise ratio $(\mathrm{S} / \mathrm{N})$ of 3. For 3-MP, noise was measured as the peak-

304 to-peak noise directly adjacent to the 3-MP peak since it is inherently present in the

305 plasma of mammals $[20,21]$. $\mathrm{Cbi}(\mathrm{CN})_{2}$ is not endogenously present in plasma, so noise

306 was measured as peak-to-peak noise from blank plasma over the full elution time of

$307 \mathrm{Cbi}(\mathrm{CN})_{2}$.

309 2.8. Stability, recovery, and matrix effects

310 To evaluate the stability of the two analytes, low and high QCs were stored at

311 various temperatures (room temperature (RT), $4{ }^{\circ} \mathrm{C},-30{ }^{\circ} \mathrm{C}$, and $-80{ }^{\circ} \mathrm{C}$ ) and analyzed at

312 multiple storage times. As stability samples were prepared for analysis, 3-MP internal

313 standard was added to help correct for sample preparation and instrumental variability.

314 The stability of $\mathrm{Cbi}(\mathrm{CN})_{2}$ and 3-MP were calculated as a percentage of the initial

315 concentration (standards were prepared each day of analysis), with the sample considered

316 stable if the concentration of the stored sample was within $10 \%$ of the standard. The

317 stability of only $\mathrm{Cbi}(\mathrm{CN})_{2}$ was determined, as the stability of the other Cbi species of

318 interest $\left(\mathrm{Cbi}\left(\mathrm{H}_{2} \mathrm{O}\right)(\mathrm{OH})^{+}\right.$and $\left.\mathrm{Cbi}\left(\mathrm{NO}_{2}\right)_{2}\right)$ are well known [15, 32]. Long-term stability

319 was conducted at three storage temperatures $\left(4{ }^{\circ} \mathrm{C},-30{ }^{\circ} \mathrm{C}\right.$, and $\left.-80{ }^{\circ} \mathrm{C}\right)$. The samples

320 were analyzed in triplicate after 1, 6, 10, 15, and 30 days. Autosampler stability of 3- 
321 MPB and $\mathrm{Cbi}(\mathrm{CN})_{2}$ was determined after typical sample preparation of low and high QCs

322 and storage in a cooled autosampler $\left(15^{\circ} \mathrm{C}\right)$ for approximately $2,4,8,12$, and 24 hours.

323 Short term stability of 3-MP and $\mathrm{Cbi}(\mathrm{CN})_{2}$ was conducted at RT, after $0,2,4,8,12$, and

32424 hours. For freeze-thaw stability of 3-MP and $\mathrm{Cbi}(\mathrm{CN})_{2}$, each set of QCs (low and

325 high) were stored at $-80^{\circ} \mathrm{C}$ for 24 hours, thawed unassisted at RT, and a single set of

326 QCs were prepared and analyzed. The remaining QCs were then placed in the $-80{ }^{\circ} \mathrm{C}$

327 freezer. This procedure was repeated for a total of three freeze-thaw cycles. A set of QC

328 standards (low and high) for 3-MP and Cbi were prepared fresh each day. Stability was

329 determined by comparing QCs to standards.

330 To determine the recovery of $\mathrm{Cbi}(\mathrm{CN})_{2}$ and 3-MP, five aqueous QCs (low,

331 medium, and high) were prepared, analyzed and compared with equivalent concentrations

332 of QCs in plasma. Recovery was calculated as a percentage by dividing the analyte

333 plasma concentration with the calculated aqueous equivalent QC concentration. Matrix

334 effects were evaluated by comparing aqueous and plasma calibration curves.

$336 \quad 3 . \quad$ Results and discussion

337 3.1. Determination of $\mathrm{Cbi}(\mathrm{CN})_{2}$ and 3-MP from swine plasma

338 Multiple species of Cbi are likely to exist in plasma samples after its

339 administration. For example, if the current formulation of $\mathrm{Cbi}\left(\mathrm{NO}_{2}\right)_{2}$ [15] is administered

340 intramuscularly to a victim of cyanide poisoning, $\mathrm{Cbi}\left(\mathrm{NO}_{2}\right)_{2}, \mathrm{Cbi}(\mathrm{CN})_{2}, \mathrm{Cbi}(\mathrm{CN})\left(\mathrm{NO}_{2}\right)$,

$341 \mathrm{Cbi}\left(\mathrm{H}_{2} \mathrm{O}\right)(\mathrm{OH})^{+}, \mathrm{Cbi}(\mathrm{CN})(\mathrm{OH})$, and other Cbi species may be present. Therefore, in order

342 to determine the total $\mathrm{Cbi}$ in a plasma sample, all $\mathrm{Cbi}$ species were converted to $\mathrm{Cbi}(\mathrm{CN})_{2}$

343 by the addition of excess cyanide $[18,32,39]$. This approach is based on the strong 
344 affinity cyanide has for the cobalt atom of Cbi, allowing cyanide to out-compete other

345 Cbi ligands and create one form of cobinamide. Once all the Cbi species are converted to

$346 \mathrm{Cbi}(\mathrm{CN})_{2}$, the total Cbi can be analyzed as $\mathrm{Cbi}(\mathrm{CN})_{2}$. Another difficulty in analyzing Cbi

347 is its affinity for haptocorrin proteins $[2,32]$. Because it is necessary to precipitate plasma

348 proteins during analysis, any protein-bound Cbi would decrease the amount of free Cbi

349 available for analysis, consequently decreasing recovery. Therefore, it was necessary to

350 denature the plasma proteins to release bound Cbi. Denaturing the plasma proteins was

351 accomplished using the combination of base and heat. Simultaneously, CN was used to

352 convert $\mathrm{Cbi}$ species to $\mathrm{Cbi}(\mathrm{CN})_{2}$, which has the added advantage of lower affinity for

353 plasma proteins than other Cbi species [18]. Others have used this approach successfully

354 to analyze total Cbi from plasma spectrophotometrically [18].

355 It is known that 3-MP degrades quickly in plasma at room temperature [28], so it

356 was inferred that it would be highly unstable when denaturing proteins at elevated

357 temperatures. Therefore, no heat was used to denature proteins when initially converting

358 Cbi species to $\mathrm{Cbi}(\mathrm{CN})_{2}$ with excess cyanide. Two concentrations of cyanide were

359 evaluated, 1.5 and $5 \mathrm{mM}$ (i.e., $3 \mathrm{x}$ and $10 \mathrm{x}$ the highest concentration $\mathrm{Cbi}(\mathrm{CN})_{2}$ calibration

360 standard tested) under mildly basic conditions (10 mM NaOH). As shown in Fig. 1, the

361 use of 1.5 and $5 \mathrm{mM}$ cyanide produced $\sim 70 \%$ and $\sim 100 \%$ conversion $\mathrm{Cbi}\left(\mathrm{NO}_{2}\right)_{2}$,

362 respectively. Although $100 \%$ of the $\mathrm{Cbi}\left(\mathrm{NO}_{2}\right)_{2}$ was converted to $\mathrm{Cbi}(\mathrm{CN})_{2}$ using $5 \mathrm{mM}$

$363 \mathrm{CN}$, only about $30 \%$ of the $\mathrm{Cbi}\left(\mathrm{H}_{2} \mathrm{O}\right)(\mathrm{OH})^{+}$was converted to $\mathrm{Cbi}(\mathrm{CN})_{2}$ at both $\mathrm{CN}$

364 concentrations tested. Although it was expected that excess CN would degrade 3-MP, it

365 was found that 3 -MP signals remained consistently $100 \pm 10$. This may be due to the rapid 
366 reactivity of $\mathrm{CN}$ with $\mathrm{Cbi}$ and multiple other components of blood, inclusively

367 minimizing the reaction of $\mathrm{CN}$ with free 3-MP.

368 The inability to fully convert $\mathrm{Cbi}\left(\mathrm{H}_{2} \mathrm{O}\right)(\mathrm{OH})^{+}$to $\mathrm{Cbi}(\mathrm{CN})_{2}$ under ambient

369 temperatures indicated that the conditions were too mild to fully release the

$370 \mathrm{Cbi}\left(\mathrm{H}_{2} \mathrm{O}\right)(\mathrm{OH})^{+}$from plasma proteins. Therefore, a harsher denaturing protocol was

371 added to the sample preparation procedure, where both higher concentrations of base and

372 elevated temperatures were evaluated. Fig. 1 shows that $5 \mathrm{mM} \mathrm{KCN}$, a higher

373 concentration of base $(0.1 \mathrm{M} \mathrm{NaOH})$, and heating at $80{ }^{\circ} \mathrm{C}$ converted both $\mathrm{Cbi}\left(\mathrm{NO}_{2}\right)_{2}$ and

$374 \mathrm{Cbi}\left(\mathrm{H}_{2} \mathrm{O}\right)(\mathrm{OH})^{+}$completely to $\mathrm{Cbi}(\mathrm{CN})_{2}(100 \pm 10 \%)$. However, as expected, 3-MP was

375 not stable at this temperature. Since the conditions to prepare 3-MP and Cbi were not

376 fully compatible, we evaluated a quasi one-pot sample preparation procedure.

377 For the quasi one-pot procedure, the samples were initially split in half and

378 prepared separately until precipitation of proteins occurred, then the prepared samples

379 were re-combined for the duration of the analysis. As shown in Fig. 1, full conversion of

380 Cbi to $\mathrm{Cbi}(\mathrm{CN})_{2}$ was successful and 3-MP was stable with the quasi one-pot procedure.

381 Therefore, the quasi one-pot sample preparation scheme was adopted for plasma sample

382 preparation in order to analyze 3-MP and $\mathrm{Cbi}(\mathrm{CN})_{2}$ simultaneously.

383 Utilizing the quasi one-pot sample preparation, Fig. 2 shows the chromatograms

384 of 3-MP (A) and $\mathrm{Cbi}(\mathrm{CN})_{2}(\mathrm{~B})$, eluting at 2.6 and 2.9 mins, respectively. Fig. 2A shows

385 four 3-MP chromatograms that are plotted from samples prepared with multiple Cbi

386 species. Each is essentially identical, indicating the presence of the Cbi species do not

387 interfere with the analysis of 3-MP. Fig. 2B, shows chromatograms of $\mathrm{Cbi}(\mathrm{CN})_{2}$ after

388 conversion from $\mathrm{Cbi}\left(\mathrm{H}_{2} \mathrm{O}\right)(\mathrm{OH})^{+}$and $\mathrm{Cbi}\left(\mathrm{NO}_{2}\right)_{2}$, each in the presence of 3-MP. The 
389 chromatograms are essentially identical to the $\mathrm{Cbi}(\mathrm{CN})_{2}$ standard, indicating that full

390 conversion of $\mathrm{Cbi}\left(\mathrm{H}_{2} \mathrm{O}\right)(\mathrm{OH})^{+}$and $\mathrm{Cbi}\left(\mathrm{NO}_{2}\right)_{2}$ was accomplished, and that 3-MP does not

391 interfere with Cbi analysis. The final combined 3-MP/Cbi method shows excellent

392 selectivity with no interfering peaks observed in the blank. In fact, in swine plasma, no

393 other peaks were observable for either 3-MPB or $\mathrm{Cbi}(\mathrm{CN})_{2}$.

395 3.2. Linear range, limit of detection, and sensitivity

396 The linear range, limit of detection, and sensitivity of the method were evaluated

397 to ensure the applicability of the method for combined 3-MP and Cbi analysis. The linear

398 range for 3-MP was $2-500 \mu \mathrm{M}$ using a $1 / \mathrm{x}^{2}$ weighted curve. Of the original concentrations

399 tested, 1 and $1000 \mu \mathrm{M}$ were excluded because they did not meet the accuracy and/or

400 precision inclusion criteria. The linear range of the current method for 3-MP was actually

401 greater than our previous study, where we analyzed 3-MP individually [28]. The linear

402 dynamic range for $\mathrm{Cbi}(\mathrm{CN})_{2}$ was $0.5-50 \mu \mathrm{M}$ using a $1 / \mathrm{x}^{2}$ weighted calibration curve. Cbi

403 calibrators at concentrations of 100,200 , and $500 \mu \mathrm{M}$ were excluded because they did not

404 meet the accuracy and/or precision inclusion criteria.

405 The LODs of $\mathrm{Cbi}(\mathrm{CN})_{2}$ and 3-MP were $0.2 \mu \mathrm{M}$ and $0.5 \mu \mathrm{M}$, respectively. The

406 LOD of 3-MP was similar our previous analysis of 3-MP alone, $0.1 \mu \mathrm{M}$ [28], but was

407 significantly higher than the $1 \mathrm{nM}$ LOD found for an HPLC method with fluorescence

408 detection [27] utilized by Ogasawara et al. The LOD for $\mathrm{Cbi}(\mathrm{CN})_{2}$ was also higher than a

409 spectrophotometric method reported by Boss et al., which generated a LOD of $30 \mathrm{nM}$

410 [31]. Although the LODs for the method reported here were higher than both the HPLC

411 and spectrophotometric methods, they are acceptable for translational studies of 3-MP 
412 and Cbi, because plasma concentrations of 3-MP and Cbi from treated animals and

413 humans are expected to be well above $1 \mu \mathrm{M}[15,19,25,26,28]$.

414 The LLOQs for 3-MP and for $\mathrm{Cbi}(\mathrm{CN})_{2}$ were $2 \mu \mathrm{M}$ and $0.5 \mu \mathrm{M}$, respectively. The

415 ULOQs were $500 \mu \mathrm{M}$ for 3-MP and $50 \mu \mathrm{M}$ for $\mathrm{Cbi}(\mathrm{CN})_{2}$. Boss et al. reported a ULOQ of

$41610 \mu \mathrm{M}$ with a linear range of 2.5 orders of magnitude. Ogasawara et al. reported a linear

417 range from 0.2 to $40 \mu \mathrm{M}$ for 3-MP, and our LC-MS-MS previous method for 3-MP alone

418 had a linear range from 0.5 to $100 \mu \mathrm{M}$. Similar to the LODs, although previous methods

419 had lower linear ranges, our linear range covers at least 2 orders of magnitude and should

420 be very useful with therapeutic studies where large concentrations are administered.

422 3.3. Accuracy and precision

423 Accuracy and precision were determined by quintuplicate analysis of low,

424 medium, and high QCs $(7.5,30$, and $150 \mu \mathrm{M}$ for 3-MP and 1.5, 7.5 and $35 \mu \mathrm{M}$ for

$425 \mathrm{Cbi}(\mathrm{CN})_{2}$ ) on three different days (within 7 calendar days; Table 1). The intra-assay

426 accuracy and precision for 3-MP were $100 \pm 9 \%$ and $<5.5 \%$ RSD, respectively. For

$427 \mathrm{Cbi}(\mathrm{CN})_{2}$, the intra-assay accuracy was $100 \pm 13 \%$ and the intra-assay precision was $<9 \%$

428 RSD. The inter-assay accuracy for $3-\mathrm{MP}$ was $100 \pm 9 \%$ and $100 \pm 10 \%$ for $\mathrm{Cbi}(\mathrm{CN})_{2}$. The

429 inter-assay precision for 3-MP was $<8.5 \%$ and $<9.5 \%$ for $\mathrm{Cbi}(\mathrm{CN})_{2} .3$-MP had better

430 accuracy and precision due to the internal standard that could correct for daily

431 instrumental variations. Even without an internal standard for $\mathrm{Cbi}(\mathrm{CN})_{2}$, the precision

432 and accuracy for the method were excellent and well within the FDA method validation

433 guidelines for both analytes. 
Our previous method for 3-MP analysis produced an accuracy and precision of

$435100 \pm 9 \%$ and $<7 \%$ RSD, respectively, in aggregate (both intra and inter assay values are

436 included) [28]. Ogasawara et al. [27] reported a better precision of $<4.8 \%$, but no

437 accuracy was presented. The precision for the analysis of total cobinamide using the Boss

438 et al. multiwavelength spectrometry method was similar, <7.6\% for all QCs [31]. The

439 likely cause of the slightly worse precision for our method compared to other similar

440 methods for single species, is differences in the instruments used and the more involved

441 sample preparation requirements for the simultaneous analysis of 3-MP and Cbi.

$443 \quad$ 3.4. Stability, recovery, and matrix effects

444 The long term stability of $\mathrm{Cbi}(\mathrm{CN})_{2}$ and 3-MP in swine plasma (i.e., both

$445 \mathrm{Cbi}(\mathrm{CN})_{2}$ and 3-MP were added to each plasma sample for stability studies) was

446 evaluated at $4,-30$, and $-80^{\circ} \mathrm{C}$, with short-term stability evaluated at room temperature

447 for $24 \mathrm{hrs}$. The low and high 3-MP QCs were stable at $-80{ }^{\circ} \mathrm{C}$ for at least 30 days, but

448 both degraded rapidly at $4{ }^{\circ} \mathrm{C}$. While the high 3-MP QC was stable at $-30{ }^{\circ} \mathrm{C}$ for at least

44930 days, the low QC was only stable for 6 days. $\mathrm{Cbi}(\mathrm{CN})_{2}$ was extremely stable, with the

450 low and high $\mathrm{Cbi}(\mathrm{CN})_{2}$ QCs stable for at least 30 days under each long-term storage

451 condition. For freeze-thaw stability, 3-MP and $\mathrm{Cbi}(\mathrm{CN})_{2}$ were both stable for all three

452 cycles. This result differs from our previous 3-MP analysis, where 3-MP was only stable

453 for one freeze-thaw cycle [28]. To determine if Cbi had a stabilizing effect on 3-MP

454 during freeze-thaw cycles, freeze-thaw stability was evaluated with 3-MP alone. The 3-

455 MP was still stable for 3 freeze-thaw cycles, indicating that $\mathrm{Cbi}(\mathrm{CN})_{2}$ did not affect the 3-

456 MP stability. In our previous method, although 3-MP was reported as stable for only one 
457 freeze-thaw cycle (i.e., within $90 \%$ of the initial analysis), it was within $80 \%$ of the initial

458 analysis for all three days [28]. Therefore, it is likely that improved sample preparation

459 and handling during the current study increased the stability of 3-MP for the second and

460 third freeze-thaw cycles. For short-term stability (at RT), 3-MP was stable for less than 4

461 hours for both the high and low QCs. The 3-MP was again more stable than in our

462 previous work [28]. The $\mathrm{Cbi}(\mathrm{CN})_{2}$ was extremely stable at $\mathrm{RT}$, with concentrations for

463 both QCs within $\pm 10 \%$ for the entire study. In the autosampler, both the prepared 3-MP,

464 as 3-MPB, and $\mathrm{Cbi}(\mathrm{CN})_{2}$ were found stable for at least 24 hours. The results from the

465 stability studies, suggest that if storage is necessary, plasma samples with 3-MP and

$466 \mathrm{Cbi}(\mathrm{CN})_{2}$ should be frozen and immediately stored at $-80{ }^{\circ} \mathrm{C}$. Once samples are thawed,

467 they should be prepared immediately and refrozen if future analysis is necessary.

468 Samples can also be stored on a cooled autosampler for at least 24 hours after

469 preparation.

470 The recovery of 3-MP for the low, medium and high QCs were 104\%, 99\% and

$47199 \%$, respectively, and no matrix effects were observed for 3-MP. Recoveries of 3-MP in

472 previous methods were 75-81\% [28] and 79-85\% [27]. Again, improved sample handling

473 is likely the reason for improved 3-MP recoveries in this study. The apparent initial

474 recoveries for $\mathrm{Cbi}(\mathrm{CN})_{2}$ were $29 \%, 29 \%$, and $33 \%$ for the low, medium, and high QCs,

475 respectively. The recoveries were highly reproducible both with and without 3-MP. To

476 determine if the apparently low recoveries for Cbi were truly due to low recovery or due

477 to matrix effects, calibration curves for $\mathrm{Cbi}(\mathrm{CN})_{2}$ were produced in aqueous solution and

478 in plasma. The slope of the $\mathrm{Cbi}(\mathrm{CN})_{2}$ plasma calibration curve was 2-3 times less than the

479 slope of the aqueous calibration curve, clearly indicating matrix effects were present for 
$480 \mathrm{Cbi}(\mathrm{CN})_{2}$ analysis from plasma. Therefore, one-half to one-third of the aqueous signal is

481 produced when the plasma matrix is present. In aggregate the extent of the matrix effects,

482 results from the stability studies, and the ability to fully convert all Cbi species to

$483 \mathrm{Cbi}(\mathrm{CN})_{2}$ (Fig. 1), indicates that the apparently low recovery was caused by matrix

484 effects. Because an internal standard for $\mathrm{Cbi}(\mathrm{CN})_{2}$ would likely correct for matrix effects,

485 the addition of an internal standard for $\mathrm{Cbi}(\mathrm{CN})_{2}$ may be an area of further improvement

486 of the method.

488 3.5. Analysis of Cbi and sulfanegen-exposed animals

489 The validated LC-MS-MS method was applied to the analysis of plasma gathered

490 from rabbits and rats treated with sulfanegen and cobinamide, respectively. The LC-MS-

491 MS analysis of sulfanegen treated rabbit and Cbi treated rat plasma is shown in Fig. 3.

492 The sulfanegen treated rabbit plasma contains greatly elevated 3-MP concentrations

493 compared to untreated rabbits. Unlike 3-MP swine samples, another peak was observed

494 in rabbit plasma (eluting at $3.15 \mathrm{~min}$ ), but was fully resolved from the 3-MP peak

$495\left(\mathrm{R}_{\mathrm{s}}=1.91\right)$. Similarly, elevated Cbi concentrations were observed with Cbi treated

496 compared to untreated rats. Overall, Fig. 3 confirms that the validated method has the

497 ability to detect 3-MP and Cbi in the plasma of sulfanegen and cobinamide treated

498 animals. In the near future, a pharmacokinetic study that utilizes sulfanegen and Cbi as a

499 combination therapeutic for cyanide poisoning will be performed using the LC-MS-MS

500 method presented here.

501

502 4. Conclusion 
504 was developed featuring simple sample preparation, rapid analysis, excellent accuracy

505 and precision, excellent limits of detection, and linear ranges of at least 2 orders of

506 magnitude. The method presented here has the ability to simultaneously analyze 3-MP

507 and Cbi from the plasma of treated animals, which will facilitate the study of sulfanegen

508 and Cbi as a combination therapy for cyanide poisoning.

\section{Acknowledgements}

511 We gratefully acknowledge the support from the CounterACT Program, National

512 Institutes of Health Office of the Director (NIH OD), and the National Institute of

513 Allergy and Infectious Diseases, (Grant Number Y1-OD-0690-01/A-120-B.P2010- 01,

514 Y1-OD-1561-01/A120-B.P2011-01, AOD14020-001-00000/A120-B.P2014-01,

515 AOD13016-001-00000/A120-B.P2013-01, AOD12060-001-00000/A120-B.P2012-01).

516 We also would like to acknowledge support by U.S. Dept. of Education GAANN award

517 (P200A100103). We thank the National Science Foundation Major Research

518 Instrumentation Program (Grant Number CHE-0922816) for funding the AB SCIEX

519 QTRAP 5500 LC/MS/MS (EPSCoR Grant 0091948). Lastly, we would like to thank the

520 South Dakota State University Campus Mass Spectrometry Facility for the use of the LC-

521 MS-MS, obtained with the support from the National Science Foundation/EPSCoR

522 (Grant Number 0091948). The opinions or assertions contained herein are the private

523 views of the authors and are not to be construed as official or as reflecting the views of

524 the national Science Foundation, the National Institute of Health, or Department of

525 Defense. 
LC-ESI-MS/MS of 3-mercaptopyruvate and cobinamide

\section{References}

528 [1] A.H. Hall, J. Saiers, F. Baud, Which cyanide antidote?, Critical Reviews in

529 Toxicology, $39(2009)$ 541-552.

530 [2] K.E. Broderick, P. Potluri, S. Zhuang, I.E. Scheffler, V.S. Sharma, R.B. Pilz, G.R.

531 Boss, Cyanide Detoxification by the Cobalamin Precursor Cobinamide, Experimental

532 Biology and Medicine, 231 (2006) 641-649.

533 [3] H.T. Nagasawa, D.J.W. Goon, D.L. Crankshaw, R. Vince, S.E. Patterson, Novel,

534 orally effective cyanide antidotes, Journal of Medicinal Chemistry, 50 (2007) 6462-6464.

535 [4] M. Sutter, N. Tereshchenko, R. Rafii, G.P. Daubert, Hemodialysis complications of

536 hydroxocobalamin: a case report, Journal of Medical Toxicology, 6 (2010) 165-167.

537 [5] J. Hamel, A review of acute cyanide poisoning with a treatment update, Critical Care

538 Nurse, 31 (2011) 72-82.

539 [6] D.J. O'Brien, D.W. Walsh, C.M. Terriff, A.H. Hall, Empiric management of cyanide

540 toxicity associated with smoke inhalation, Prehospital and Disaster Medicine, 26 (2011)

$541 \quad 374-382$.

542 [7] S.W. Borron, F.J. Baud, P. Barriot, M. Imbert, C. Bismuth, Prospective Study of

543 Hydroxocobalamin for Acute Cyanide Poisoning in Smoke Inhalation, Annals of

544 Emergency Medicine, 49 (2007) 794-801.

545 [8] A.H. Hall, R. Dart, G. Bogdan, Sodium Thiosulfate or Hydroxocobalamin for the

546 Empiric Treatment of Cyanide Poisoning?, Annals of Emergency Medicine, 49 (2007)

$547 \quad 806-813$. 
548 [9] C.A. DesLauriers, A.M. Burda, M. Wahl, Hydroxocobalamin as a Cyanide Antidote,

549 American Journal of Therapeutics, 13 (2006) 161-165.

550 [10] C.E. Becker, N.L. Benowitz, J.C. Forsyth, A.H. Hall, P.D. Mueller, J. Osterloh,

551 Hydroxocobalamin as a cyanide antidote: safety, efficacy and pharmacokinetics in

552 heavily smoking normal volunteers, Journal of Toxicology: Clinical Toxicology, 31

553 (1993) 277-294.

554 [11] C. Brunel, C. Widmer, M. Augsburger, F. Dussy, T. Fracasso, Antidote treatment for

555 cyanide poisoning with hydroxocobalamin causes bright pink discolouration and

556 chemical-analytical interferences, Forensic Science International, 223 (2012) 10-12.

557 [12] K.E. Broderick, L. Alvarez, M. Balasubramanian, D.D. Belke, A. Makino, A. Chan,

558 V.L. Woods, W.H. Dillmann, V.S. Sharma, R.B. Pilz, T.D. Bigby, G.R. Boss, Nitrosyl-

559 cobinamide, a new and direct nitric oxide-releasing drug effective in vivo, Society for

560 Experimental Biology and Medicine, 232 (2007) 1432-1440.

561 [13] V.S. Sharma, R.B. Pilz, G.R. Boss, D. Magde, Reactions of nitric oxide with vitamin

562 B12 and its precursor, cobinamide, Biochemistry, 42 (2003) 8900-8908.

563 [14] G. Hayward, H. Hill, J. Pratt, N. Vanston, R. Williams, 1196. The chemistry of

564 vitamin B12. Part IV. The thermodynamic trans-effect, Journal of the Chemical Society,

565 (1965) 6485-6493.

566 [15] A. Chan, J. Jiang, A. Fridman, L.T. Guo, G.D. Shelton, M. Liu, C. Green, K.J.

567 Haushalter, H.H. Patel, J. Lee, Y. David, T. Burney, D. Mukai, S.B. Mahon, M. Brenner,

568 R.B. Pilz, G.R. Boss, Nitrocobinamide, a New Cyanide Antidote That Can Be

569 Administered by Intramuscular Injection, Journal of Medicinal Chemistry, 58 (2015)

$570 \quad 1750-1759$. 
571 [16] A. Chan, D.L. Crankshaw, A. Monteil, S.E. Patterson, H.T. Nagasawa, J.E. Briggs,

572 J.A. Kozocas, S.B. Mahon, M. Brenner, R.B. Pilz, T.D. Bigby, G.R. Boss, The

573 combination of cobinamide and sulfanegen is highly effective in mouse models of

574 cyanide poisoning, Clinical Toxicology, 49 (2011) 366-373.

575 [17] M. Brenner, S.B. Mahon, J. Lee, J. Kim, D. Mukai, S. Goodman, K.A. Kreuter, R.

576 Ahdout, O. Mohammad, V.S. Sharma, W. Blackledge, G.R. Boss, Comparison of

577 cobinamide to hydroxocobalamin in reversing cyanide physiologic effects in rabbits

578 using diffuse optical spectroscopy monitoring, Journal of Biomedical Optics, 15 (2010)

579 017001-017001.

580 [18] A. Chan, M. Balasubramanian, W. Blackledge, O.M. Mohammad, L. Alvarez, G.R.

581 Boss, T.D. Bigby, Cobinamide is superior to other treatments in a mouse model of

582 cyanide poisoning, Clinical Toxicology, 48 (2010) 709-717.

583 [19] M. Brenner, J.G. Kim, J. Lee, S.B. Mahon, D. Lemor, R. Ahdout, G.R. Boss, W.

584 Blackledge, L. Jann, H.T. Nagasawa, S.E. Patterson, Sulfanegen sodium treatment in a

585 rabbit model of sub-lethal cyanide toxicity, Toxicology and Applied Pharmacology, 248

586 (2010) 269-276.

587 [20] G.E. Isom, J.L. Borowitz, S. Mukhopadhyay, Sulfurtransferase Enzymes Involved in

588 Cyanide Metabolism, in: C. McQueen (Ed.) Comprehensive Toxicology 2010, pp. 485-

589500.

590 [21] A. Spallarossa, F. Forlani, A. Carpen, A. Armirotti, S. Pagani, M. Bolognesi, D.

591 Bordo, The "Rhodanese" Fold and Catalytic Mechanism of 3-Mercaptopyruvate

592 Sulfurtransferases: Crystal Structure of SseA from Escherichia coli, Journal of Molecular

593 Biology, 335 (2004) 583-593. 
594 [22] N. Nagahara, T. Ito, M. Minami, Mercaptopyruvate sulfurtransferase as a defense

595 against cyanide toxication. Molecular properties and mode of detoxification, Histology

596 and Histopathology, 14 (1999) 1277-1286.

597 [23] M. Wróbel, H. Jurkowska, L. Śliwa, Z. Srebro, Sulfurtransferases and cyanide

598 detoxification in mouse liver, kidney, and brain, Toxicology Mechanisms and Methods,

$59914(2004) 331-337$.

600 [24] A.A. Al-Qarawi, H.M. Mousa, B.H. Ali, Tissue and intracellular distribution of

601 rhodanese and mercaptopyruvate sulphurtransferase in ruminants and birds, Veterinary

602 Research, 32 (2001) 63-70.

603 [25] S.E. Patterson, A.R. Monteil, J.F. Cohen, D.L. Crankshaw, R. Vince, H.T.

604 Nagasawa, Cyanide Antidotes for Mass Casualties: Water-Soluble Salts of the Dithiane

605 (Sulfanegen) from 3-Mercaptopyruvate for Intramuscular Administration, Journal of

606 Medicinal Chemistry, 56 (2013) 1346-1349.

607 [26] K.G. Belani, H. Singh, D.S. Beebe, P. George, S.E. Patterson, H.T. Nagasawa, R.

608 Vince, Cyanide toxicity in juvenile pigs and its reversal by a new prodrug, sulfanegen

609 sodium, Anesthesia and Analgesia, 114 (2012) 956-961.

610 [27] Y. Ogasawara, T. Hirokawa, K. Matsushima, S. Koike, N. Shibuya, S. Tanabe, K.

611 Ishii, A novel method for the analysis of 3-mercaptopyruvate using high-performance

612 liquid chromatography with fluorescence detection, Journal of Chromatography B, 931

613 (2013) 56-60.

614 [28] M.W. Stutelberg, C.V. Vinnakota, B.L. Mitchell, A.R. Monteil, S.E. Patterson, B.A.

615 Logue, Determination of 3-mercaptopyruvate in rabbit plasma by high performance 
LC-ESI-MS/MS of 3-mercaptopyruvate and cobinamide

616 liquid chromatography tandem mass spectrometry, Journal of Chromatography B, 949-

617950 (2014) 94-98.

618 [29] R.H. Allen, S.P. Stabler, Identification and quantitation of cobalamin and cobalamin 619 analogues in human feces, The American Journal of Clinical Nutrition, 87 (2008) 13246201335.

621 [30] Y. Men, E.C. Seth, S. Yi, T.S. Crofts, R.H. Allen, M.E. Taga, L. Alvarez - Cohen, 622 Identification of specific corrinoids reveals corrinoid modification in dechlorinating 623 microbial communities, Environmental Microbiology, (2014) 1-12.

624 [31] J. Ma, P.K. Dasgupta, W. Blackledge, G.R. Boss, Cobinamide-based cyanide 625 analysis by multiwavelength spectrometry in a liquid core waveguide, Analytical 626 Chemistry, 82 (2010) 6244-6250.

627 [32] J. Ma, P.K. Dasgupta, F.H. Zelder, G.R. Boss, Cobinamide chemistries for 628 photometric cyanide determination. A merging zone liquid core waveguide cyanide 629 analyzer using cyanoaquacobinamide, Analytica Chimica Acta, 736 (2012) 78-84.

630 [33] S.H. Ford, A. Nichols, M. Shambee, The preparation and characterization of the 631 diaquo-forms of several incomplete corrinoids: cobyric acid, cobinamide, and three 632 isomeric cobinic acid pentaamides, Journal of Inorganic Biochemistry, 41 (1991) 235633244.

634 [34] S.H. Ford, J. Gallery, A. Nichols, M. Shambee, High-performance liquid 635 chromatographic analysis of the (cyanoaquo) stereoisomers of several putative vitamin B 63612 precursors, Journal of Chromatography A, 537 (1991) 235-247.

637 [35] A. Astier, F.J. Baud, Simultaneous determination of hydroxocobalamin and its 638 cyanide complex cyanocobalamin in human plasma by high-performance liquid 
639 chromatography Application to pharmacokinetic studies after high-dose

640 hydroxocobalamin as an antidote for severe cyanide poisoning, Journal of

641 Chromatography B: Biomedical Sciences and Applications, 667 (1995) 129-135.

642 [36] F. Blanche, D. Thibaut, M. Couder, J.-C. Muller, Identification and quantitation of

643 corrinoid precursors of cobalamin from Pseudomonas denitrificans by high-performance

644 liquid chromatography, Analytical Biochemistry, 189 (1990) 24-29.

645 [37] Guide for the Care and Use of Laboratory Animals, 8th ed., The National Academies

646 Press, Washington, D.C., 2011.

647 [38] Food and Drug Administration Guidance for industry bioanalytical method

648 validation, Rockville, MD, 2001.

649 [39] K. Zhou, F. Zelder, One-step synthesis of $\alpha / \beta$ cyano-aqua cobinamides from vitamin 650 B12 with Zn (II) or Cu (II) salts in methanol, Journal of Porphyrins and Phthalocyanines, $651 \quad 15(2011) 555-559$.

652

653 


\section{Figure Captions}

655

656 Fig. 1 Various attempts to fully convert Cbi species $\left(\mathrm{Cbi}\left(\mathrm{H}_{2} \mathrm{O}\right)(\mathrm{OH})^{+}\right)$and $\left.\mathrm{Cbi}\left(\mathrm{NO}_{2}\right)_{2}\right)$ to

$657 \mathrm{Cbi}(\mathrm{CN})_{2}$, while monitoring 3-MP stability. The use of 1.5 or $5 \mathrm{mM} \mathrm{CN}$ and base (10

$658 \mathrm{mM})$ with or without heat $\left(80^{\circ} \mathrm{C}\right)$ to denature plasma proteins did not fully convert

$659 \mathrm{Cbi}\left(\mathrm{H}_{2} \mathrm{O}\right)(\mathrm{OH})^{+}$to $\mathrm{Cbi}(\mathrm{CN})_{2}$. The use of $5 \mathrm{mM} \mathrm{CN}$ with base $(100 \mathrm{mM})$ and heat $\left(80{ }^{\circ} \mathrm{C}\right)$

660 fully converted all Cbi species to $\mathrm{Cbi}(\mathrm{CN})_{2}$ but degraded 3-MP. The quasi one-pot

661 method allowed full conversion of Cbi species to $\mathrm{Cbi}(\mathrm{CN})_{2}$ and protection of the 3-MP.

663 Fig. 2 LC-MS-MS analysis of 3-MP and $\mathrm{Cbi}(\mathrm{CN})_{2}$ analytes in swine plasma. A) The

664 chromatograms (MRM 311 $\rightarrow 223 \mathrm{~m} / \mathrm{z}$ ) represent the signal response of 3-MP, eluting at 6652.65 min, prepared from plasma with varying Cbi species and excess cyanide. B)

666 Chromatograms of multiple species of Cbi with 3-MP and excess cyanide after 667 conversion to $\mathrm{Cbi}(\mathrm{CN})_{2}$. The $\mathrm{Cbi}(\mathrm{CN})_{2}$ elutes at $2.91 \mathrm{~min}$. The chromatograms represent 668 the signal response of the MRM transition of $1015.9 \rightarrow 930.5 \mathrm{~m} / \mathrm{z}$.

670 Fig. 3 A) The LC-MS-MS chromatograms from sulfanegen treated rabbits compared to

671 3-MP spiked rabbit and swine plasma, and blank plasma with all 3-MP samples eluting at 6722.65 mins. B) Cbi treated rats compared to spiked $\mathrm{Cbi}(\mathrm{CN})_{2}$ swine and rat plasma and 673 blank plasma, with $\mathrm{Cbi}(\mathrm{CN})_{2}$ eluting at $2.9 \mathrm{~min}$. Treated rats with Cbi and spiked plasma 674 have the same retention time of $\mathrm{Cbi}(\mathrm{CN})_{2}$. Non-spiked and spiked 3-MP or $\mathrm{Cbi}(\mathrm{CN})_{2}$ 675 swine can be seen in Fig. 2. 
LC-ESI-MS/MS of 3-mercaptopyruvate and cobinamide

676 Table Caption

677 Table 1. The accuracy and precision of 3-mercaptopyruvate and $\mathrm{Cbi}(\mathrm{CN})_{2}$ analysis

678 spiked in swine plasma by LC-MS-MS.

679

680 
LC-ESI-MS/MS of 3-mercaptopyruvate and cobinamide

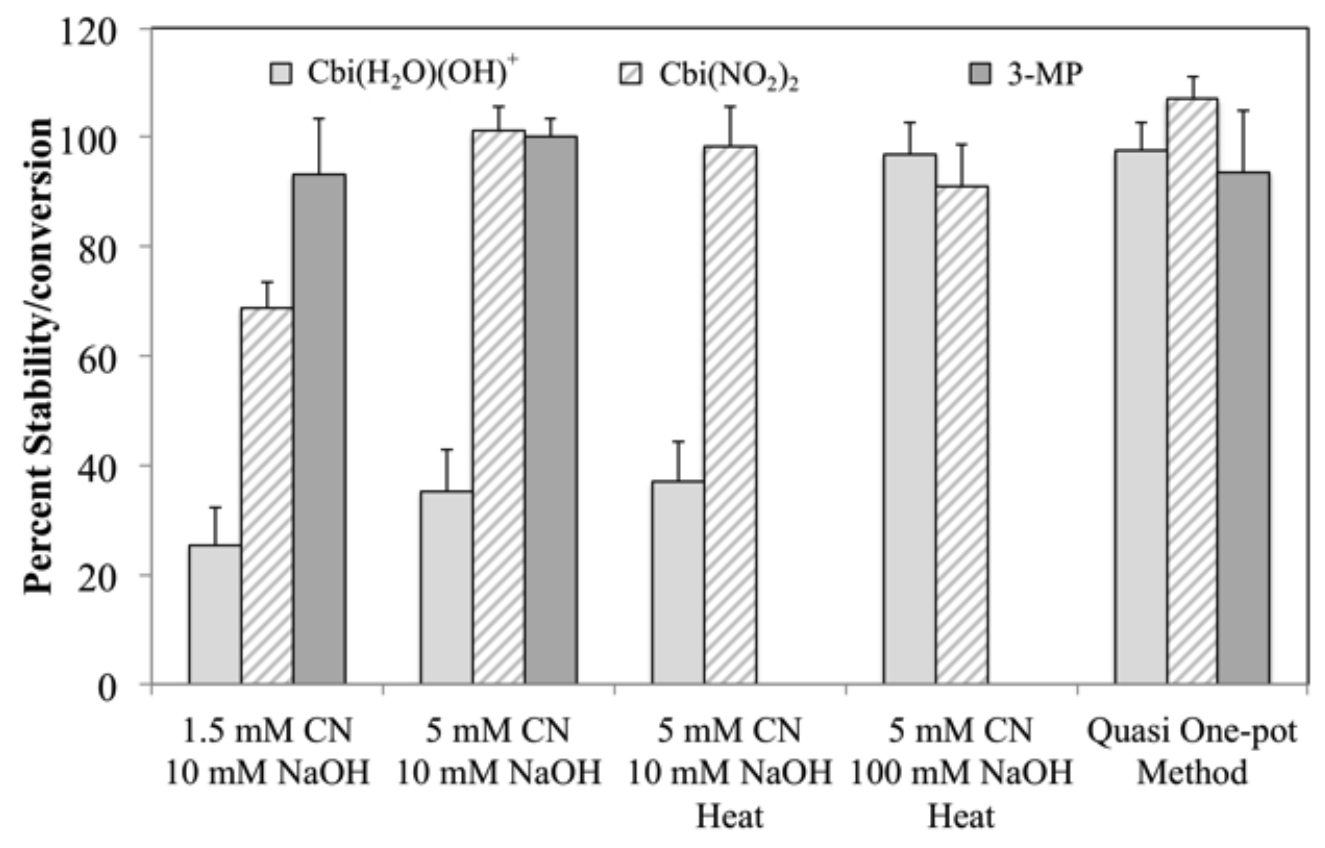

681

682 


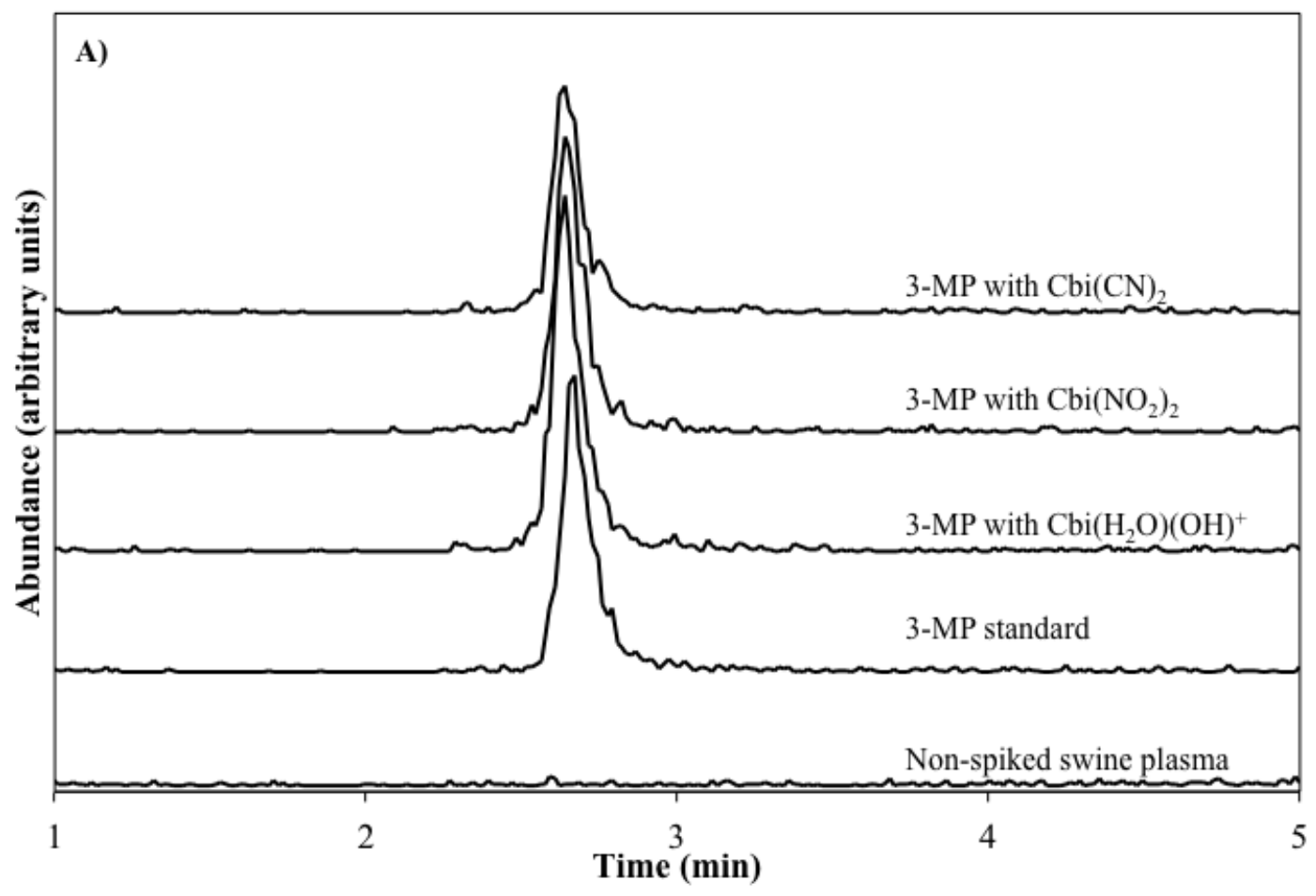




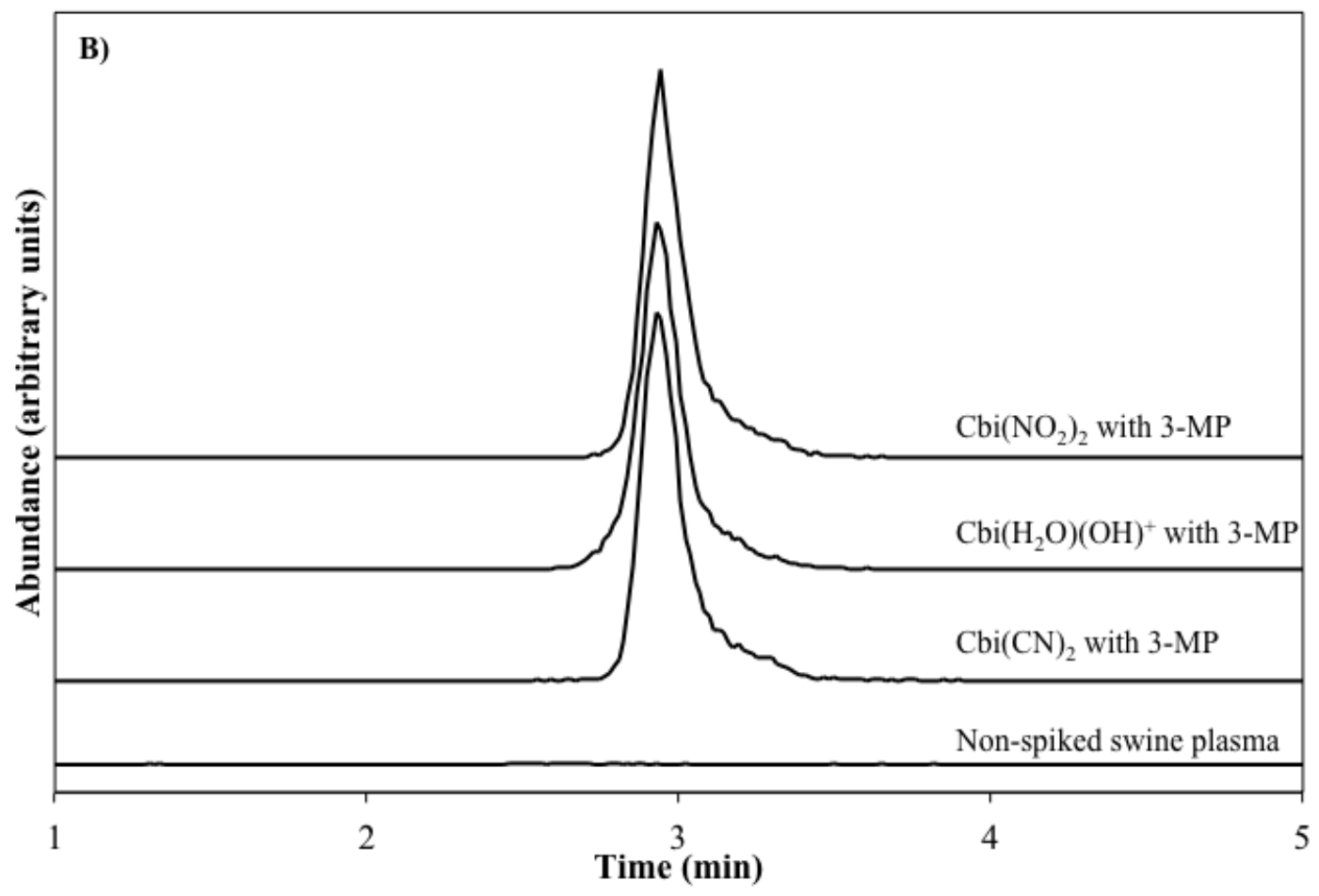

685

686 


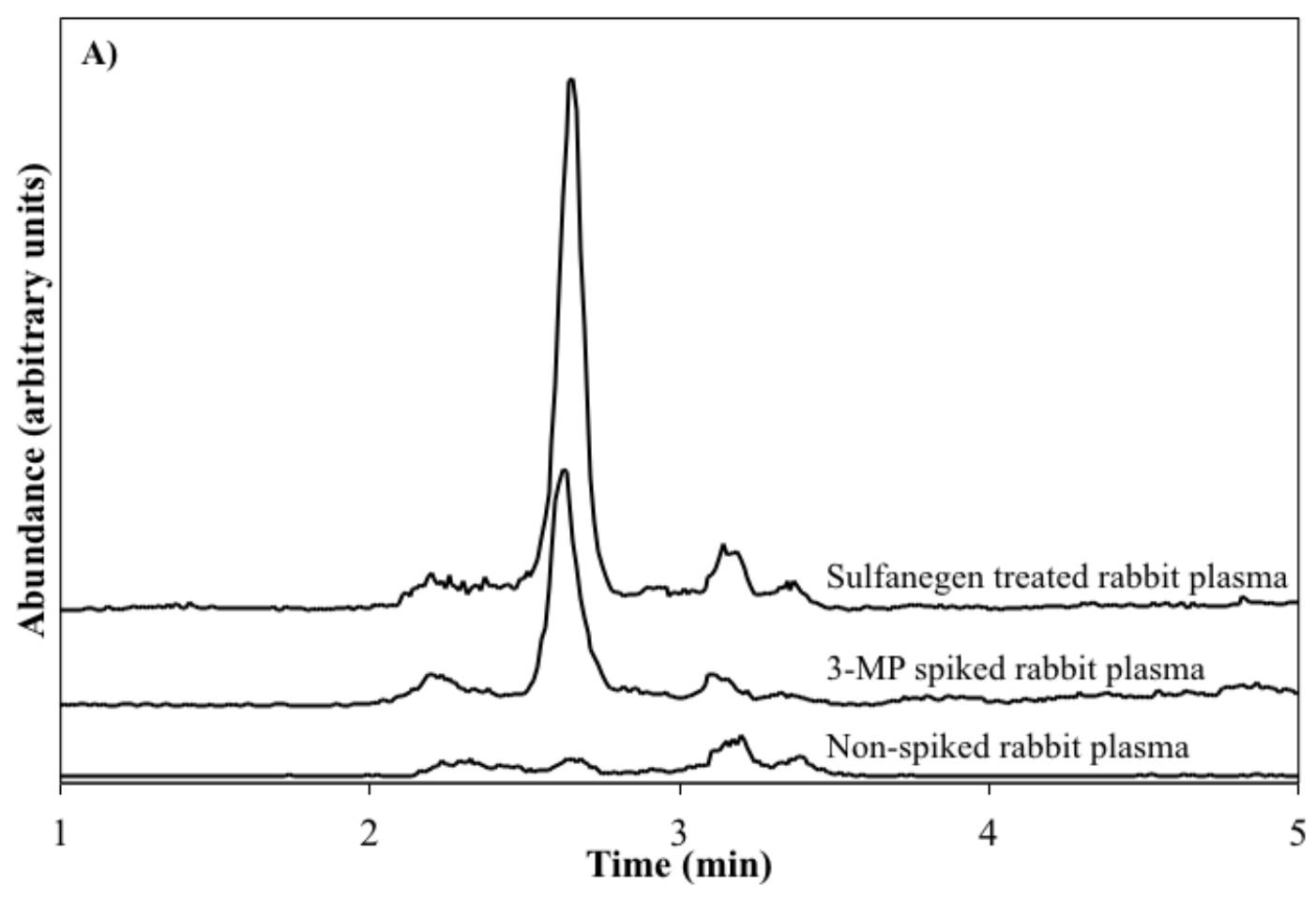




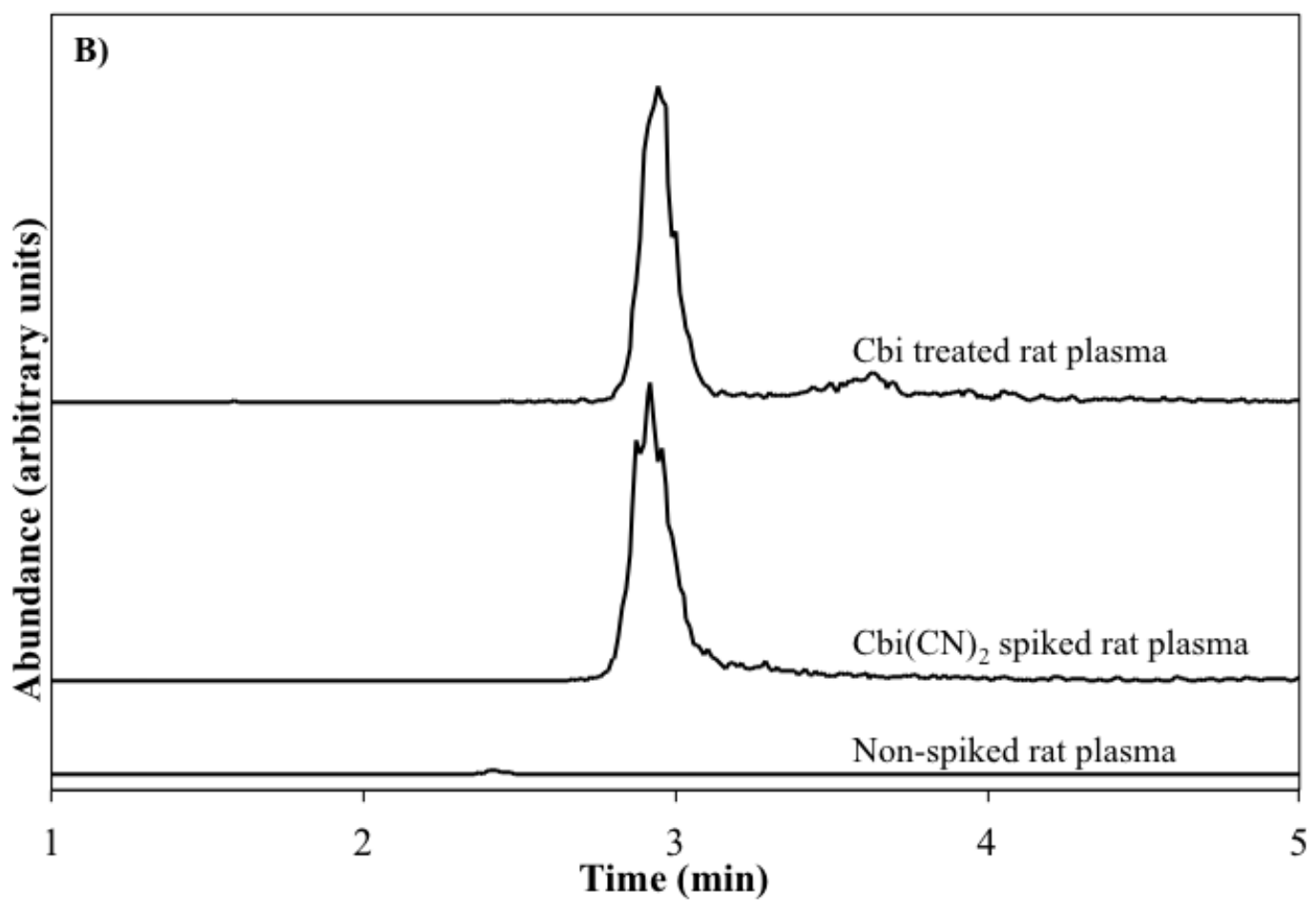




\begin{tabular}{|c|c|c|c|c|c|}
\hline Analyte & $\begin{array}{c}\text { Concentration } \\
\qquad(\mu \mathrm{M})\end{array}$ & $\begin{array}{c}\text { Intra-assay } \\
\operatorname{Accuracy}^{a}(\%)\end{array}$ & $\begin{array}{c}\text { Intra-assay } \\
\text { Precision }^{\mathrm{a}} \\
\text { (\% RSD) }\end{array}$ & $\begin{array}{c}\text { Inter-assay } \\
\text { Accuracy }^{b}(\%)\end{array}$ & $\begin{array}{c}\text { Inter-assay } \\
\text { Precision }^{\mathrm{b}} \\
\text { (\% RSD) }\end{array}$ \\
\hline \multirow[t]{3}{*}{ 3-MP } & 7.5 & $100 \pm 4$ & 5.24 & $100 \pm 5$ & 8.22 \\
\hline & 30 & $100 \pm 9$ & 2.57 & $100 \pm 9$ & 5.83 \\
\hline & 150 & $100 \pm 5$ & 5.12 & $100 \pm 6$ & 8.34 \\
\hline \multirow[t]{3}{*}{$\mathrm{Cbi}(\mathrm{CN})_{2}$} & 1.5 & $100 \pm 7$ & 7.96 & $100 \pm 10$ & 8.43 \\
\hline & 7.5 & $100 \pm 10$ & 2.73 & $100 \pm 9$ & 9.47 \\
\hline & 35 & $100 \pm 13$ & 8.99 & $100 \pm 7$ & 6.48 \\
\hline
\end{tabular}

${ }^{\mathrm{a}} \mathrm{QC}$ method validation $(\mathrm{N}=5)$ for Day 1 .

${ }^{\mathrm{b}} \mathrm{QC}$ mean from three different days of method validation $(\mathrm{N}=15)$. 692

693

694 